\title{
Meta-analysis of the effects of ischemic postconditioning on structural pathology in ST-segment elevation acute myocardial infarction
}

\author{
Baohui Lou' ${ }^{1}$, Yadong Cui ${ }^{1,3}$, Haiyang Gao² and Min Chen ${ }^{1}$ \\ ${ }^{1}$ Department of Radiology, Beijing Hospital, National Center of Gerontology, Beijing, China \\ ${ }^{2}$ Department of Cardiology, Beijing Hospital, National Center of Gerontology, Beijing, China \\ ${ }^{3}$ Graduate School of Peking Union Medical College, Beijing, China \\ Correspondence to: Min Chen, email: cjr_chenmin@126.com
}

Keywords: local ischemic postconditioning; remote ischemic postconditioning; acute myocardial infarction; cardiac magnetic resonance imaging; structural effect

Received: June 19, 2017 Accepted: October 05, 2017 Published: December 16, 2017

Copyright: Lou et al. This is an open-access article distributed under the terms of the Creative Commons Attribution License 3.0 (CC BY 3.0), which permits unrestricted use, distribution, and reproduction in any medium, provided the original author and source are credited.

\section{ABSTRACT}

In this meta-analysis, we assessed cardiac magnetic resonance imaging data to determine the effects of local and remote ischemic postconditioning (LPoC and RPoC, respectively) on structural pathology in ST-segmentel elevation acute myocardial infarction (STEMI).We searched the Pubmed, Embase and Cochrane Library databases up to May 2017 and included 12 randomized controlled trials (10 LPoC and 2 RPoC) containing 1069 study subjects with thrombolysis in myocardial infarction flow grade 0 1. Weighed mean difference (WMD), standardized mean difference (SMD), and odds ratio (OR) were used for the pooled analysis. Random-effect model was used for the potential clinical inconsistency. LPOC and RPoC increased the myocardial salvage index ( $n=5$; weighted mean difference $\left.(W M D)=5.52 ; P=0.005 ; I^{2}=76.0 \%\right)$, and decreased myocardial edema $\left(n=7 ; W M D=-3.35 ; P=0.0009 ; I^{2}=18.0 \%\right)$. However, LPoC and RPoC did not reduce the final infarct size $(n=10 ;$ WMD $=-1.01 ; P>0.05$; $\left.I^{2}=68.0 \%\right)$, left ventricular volume $(n=10$; standardized mean difference $=0.23$; $\left.P>0.05 ; \mathrm{I}^{2}=93.0 \%\right)$, the incidence of microvascular obstruction $(n=6 ; 0 R=0.99$; $\left.P>0.05 ; I^{2}=0.0 \%\right)$ or the extent of microvascular obstruction $(n=3 ;$ WMD $=-0.09$; $P>0.05 ; I^{2}=6.0 \%$ ). This meta-analysis shows that LPoC and/or RPoC improves myocardial salvage and decreases myocardial edema in STEMI patients without affecting final infarct size, left ventricular volume or microvascular obstruction.

\section{INTRODUCTION}

Timely restoration of coronary perfusion is the most effective strategy to limit infarction size (IS) and improve clinical outcomesin patients with ST-segment elevation acute myocardial infarction (STEMI) [1]. However, the progressive changes in structure and morphology of the left ventricle after ischemic myocardial reperfusion is associated with $25 \%$ of heart failure (HF) cases $[2,3]$. Hence, accurate evaluation of the effects of STEMI therapy on cardiac structural pathology is critical [4].

Ischemic postconditioning (PoC) by brief, repetitive cycles of ischemia and reperfusion in the heart (local postconditioning, LPoC) $[5,6]$ or limbs (remote postconditioning, RPoC) $[7,8]$ during early reperfusion has been shown to reduce ischemia [9]. The effect of ischemic postconditioning on cardiac enzyme levels and left ventricular function have been confirmed in the clinical trials of acute myocardial infarction (AMI) [10-12]. However, the findings on the effects of ischemic postconditioning on structural pathologyof STEMI because of the variety of imaging techniquesused such as angiography [13], echocardiography $[14,15]$, and single-photonemission computed tomography (SPECT) [16].

Cardiac magnetic resonance imaging (cMRI) has emerged as the most accurate and reliable tool for the evaluation of cardiac structure. Moreover, contrast-enhanced cMRI has been widely used to measure the infarct size with 
high spatial resolution [17-19] .In addition toventricular dimensions and infarct size, cMRI simultaneously measures myocardial salvage index (MSI), microvascular obstruction (MVO), and myocardial edema todetermine area at risk (AAR) inhigh-quality cross-sectionalimages, therebyenabling accurate anatomicaldelineation [20]. cMRI detection has also been employed in clinical trials to determine the clinical utility of PoC in STEMI [21-24]. Therefore, we conducted a comprehensive meta-analysis of clinical trials that have used cMRI to identify the potential benefits of LPoC and RPoC in STEMI patients.

\section{RESULTS}

\section{Study selection strategy}

We searched Pubmed, MEDLINE and Cochrane library databases and identified 338potential studies after excluding articles that were duplications, reviews, experimental designs, and other irrelevant contents (Figure 1). We further excluded 79 studies that were systematic reviews $(n=10)$, non-English reports $(n=3)$, had same trial numbers $(n=5)$, were non-RCT $(n=2)$, and endothelial trials $(n=8)$, studied STEMI patients with
Thrombolysis in myocardial infarction (TIMI) flow grade $\geq 2(n=3)$, and non-STEMI patients $(n=20)$ and for not reporting the primary endpoints of interest $(n=28)$. Finally, we included 12 trials $[13,14,21-30]$ with 1069STEMI patients(LPoC, $(n=920 ;$ RPoC, $(n=149)$ undergoing cMRI assessment after percutaneous coronary intervention (PCI) (Figure 1).

\section{Study characteristics}

The study design and patient characteristics are summarized in Tables 1 and 2. The LPoC protocol [cycles $\times$ ischemia/reperfusion $(\mathrm{I} / \mathrm{R})]$ was $4 \times 60 \mathrm{~s} / 60 \mathrm{~s}$ in eight studies $[13,14,22,25,26,28-30]$, and $4 \times 30 \mathrm{~s} / 30 \mathrm{~s}$ in two studies [21, 27]. The RPoC protocol (cycles $\times$ I/R) was $3 \times 5 \mathrm{~min} / 5 \mathrm{~min}$ in both studies that reported it [23, 24]. The symptom-to-balloon time was $2.92-5.47 \mathrm{~h}$, and the TIMI flow grade was $0 \sim 1$. The patients were followed up for 12 months. Final infarct size (IS) was reported in 10LPoC-related [13, 14, 21-27, 30] and twoRPoC-related $[23,24]$ studies. Myocardial salvage index (MSI) was reported in fiveLPoC-related $[22,27,28,30]$ and 1 RPoCrelated [24] studies. Myocardial edema was reported in seven LPoC-related [21, 22, 26, 27, 30] and two RPoC-

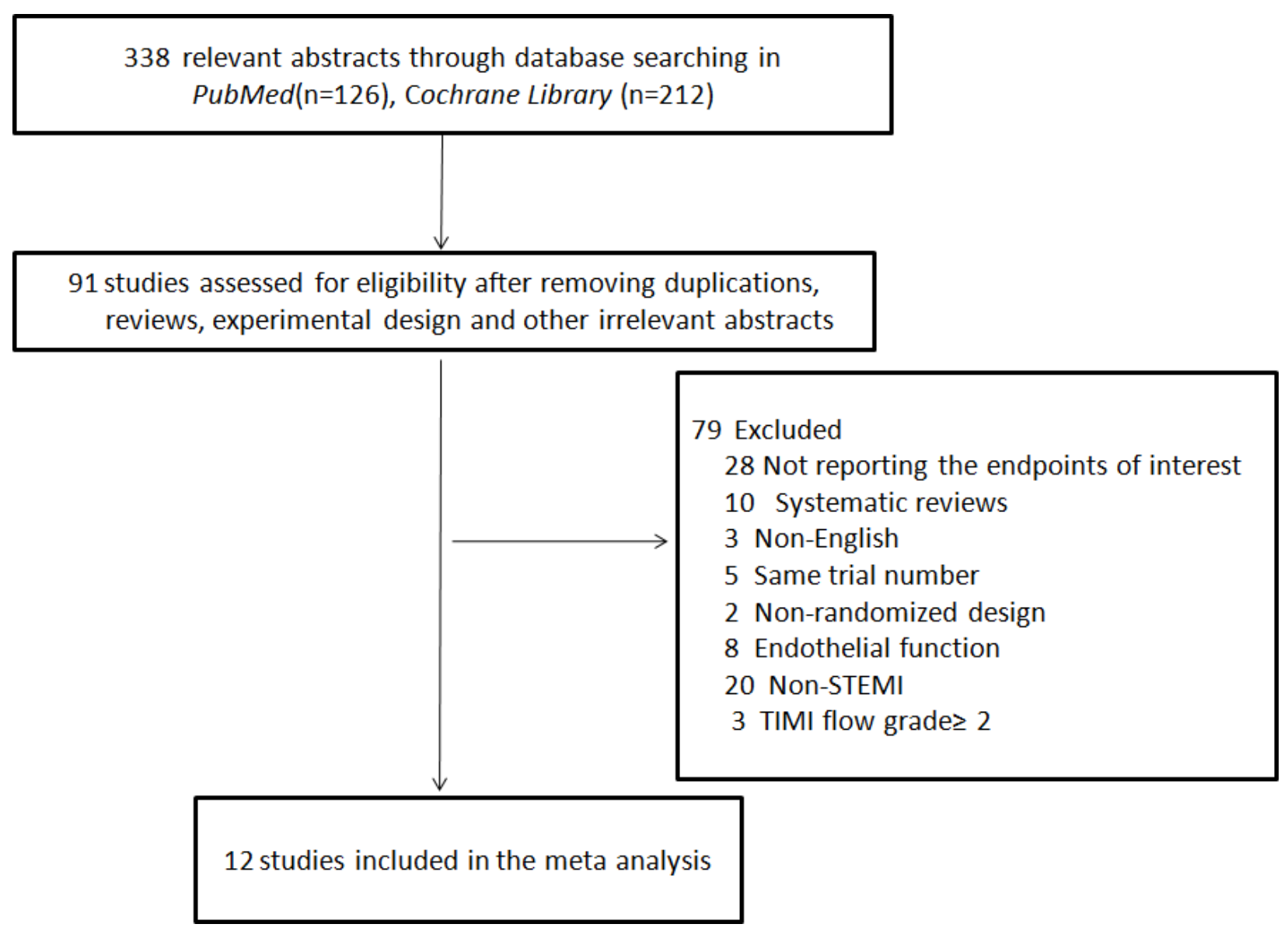

Figure 1: Flow chart of the literature search and selection strategy of eligible studies. The flow chart shows search and selection of cMRI imaging studies on the status of structural pathology of ST-segmental elevation myocardial infarction (STEMI) patients with thrombolysis in myocardial infarction (TIMI)grade $0 \sim 1$ that underwent percutaneous coronary intervention (PCI). 
Table 1: Summarized study design of the included randomized trials

\begin{tabular}{|c|c|c|c|c|c|c|c|c|c|c|c|}
\hline Study & Country & AMI & $\begin{array}{l}\text { TIMI flow } \\
\text { grade }\end{array}$ & Protocol Algorithm & $\begin{array}{l}\text { Conditioning } \\
\text { Delay(s) }\end{array}$ & $\frac{\text { Pts. No. }}{\text { PoC vs Ctrl }}$ & Clinical Endpoints & $\begin{array}{l}\text { Symptom- } \\
\text { to-balloon (h) }\end{array}$ & $\begin{array}{l}\text { Cardiac } \\
\text { Imaging }\end{array}$ & Follow-up & $\begin{array}{r}\text { Jadad } \\
\text { score }\end{array}$ \\
\hline \multicolumn{12}{|l|}{ LPoC } \\
\hline Lonborg $2010^{[21]}$ & Denmark & STEMI & $0 \sim 1$ & $30 \mathrm{~s}^{\wedge} 4$ & $<60 \mathrm{~s}$ & 43 vs 43 & IS, ME & 4.16 & CMR & 3 mons & 3 \\
\hline Sörensson $2010^{[25]}$ & Sweden & STEMI & 0 & $60 \mathrm{~s}^{\wedge} 4$ & $60 \mathrm{~s}$ & 33 vs 35 & IS,MVO, LVEDVI & 2.92 & CMR & 12 mons & 2 \\
\hline Frexia $2012^{[13]}$ & Spain & STEMI & $0 \sim 1$ & $60 \mathrm{~s}^{\wedge} 4$ & $60 \mathrm{~s}$ & 31 vs 31 & IS, MVO. LVEDV & 5.47 & CMR & 6 mons & 5 \\
\hline Taraniti $2012^{[14]}$ & Italy & STEMI & $0 \sim 1$ & $60 \mathrm{~s}^{\wedge} 4$ & $<60 \mathrm{~s}$ & 37 vs 38 & IS, MVO, LVEDVI & 3.38 & CMR & $1 \mathrm{mon}$ & 3 \\
\hline Thuny $2012^{[26]}$ & France & STEMI & $0 \sim 1$ & $60 \mathrm{~s}^{\wedge} 4$ & $<60 \mathrm{~s}$ & 25 vs 25 & $\begin{array}{c}\text { IS, } \\
\text { ME, LVEDVI }\end{array}$ & 4.20 & CMR & 4 days & 3 \\
\hline Dwyer 2013 ${ }^{[27]}$ & Canada & STEMI & $0 \sim 1$ & $30 \mathrm{~s}^{\wedge} 4$ & $<60 \mathrm{~s}$ & 39 vs 40 & $\begin{array}{c}\text { MSI, } \\
\text { ME, LVEDVI }\end{array}$ & 2.66 & CMR & 5 days & 3 \\
\hline $\begin{array}{l}\text { Limalanathan } \\
2013^{[28]}\end{array}$ & Norway & STEMI & $0 \sim 1$ & $60 \mathrm{~s}^{\wedge} 4$ & $60 \mathrm{~s}$ & 120 vs 129 & MSI & 3.00 & CMR & 4 mons & 3 \\
\hline Elzbieciak 2013 $3^{[29]}$ & Poland & STEMI & $0 \sim 1$ & $60 \mathrm{~s}^{\wedge} 4$ & $<60 \mathrm{~s}$ & 18 vs 21 & LVEDV & 4.59 & CMR & 3 mons & 2 \\
\hline $\operatorname{Kim} 2015^{[22]}$ & Korea & STEMI & $0 \sim 1$ & $60 \mathrm{~s}^{\wedge} 4$ & $<60 \mathrm{~s}$ & 56 vs 55 & $\begin{array}{l}\text { IS, MSI,MVO, } \\
\text { ME, LVEDVI }\end{array}$ & 4.77 & CMR & 3 days & 3 \\
\hline Bodi 2014[30] & Spain & STEMI & $0 \sim 1$ & $60 \mathrm{~s}^{\wedge} 4$ & $60 \mathrm{~s}$ & 49 vs 52 & $\begin{array}{l}\text { IS, MSI,MVO, } \\
\text { ME, LVEDVI }\end{array}$ & 3.20 & CMR & 6 days & 3 \\
\hline \multicolumn{12}{|l|}{$\mathrm{RPoC}$} \\
\hline Crimi $2013^{[23]}$ & Italy & STEMI & $0 \sim 1$ & $\begin{array}{c}3 \times 5 \mathrm{~min} / 5 \mathrm{~min} \text { at lower } \\
\operatorname{limb}(200 \mathrm{mmHg})\end{array}$ & Immediately & 30 vs 36 & $\begin{array}{l}\text { IS, MVO, } \\
\text { ME }\end{array}$ & 3.01 & CMR & 4 mons & 5 \\
\hline White 2014 ${ }^{[24]}$ & UK & STEMI & $0 \sim 1$ & $\begin{array}{c}3 \times 5 \mathrm{~min} / 5 \mathrm{~min} \text { at upper } \\
\operatorname{limb}(200 \mathrm{mmHg})\end{array}$ & Immediately & 43 vs 40 & $\begin{array}{l}\text { IS, MSI, MVO, } \\
\text { ME }\end{array}$ & 3.10 & CMR & 6 day & 5 \\
\hline
\end{tabular}

Note: AMI, acute myocardial infarction; STEMI, ST-segmental elevation myocardial infarction; TIMI, Thrombolysis In Myocardial Infarction ;Pts. No., patient number; IS, infarct size; MSI, myocardial salvage index; MVO, microvascular obstruction; ME, myocardial edema; LVEDV, left ventricular end-diastolic volume; LVEDVI, indexed LVEDV; CMR, cardiac magnetic resonance imaging; N.A, not available; LPoC, local ischemic postconditioning; RPoC, remote ischemic postconditioning; Ctrl, control.

\section{Table 2: Summarized patient characteristics of the included randomized trials}

\begin{tabular}{|c|c|c|c|c|c|c|c|c|c|c|c|c|}
\hline Study & Age & Male(\%) & DM(\%) & HP(\%) & Smk (\%) & DysLip(\%) & $\begin{array}{c}\text { Muti- } \\
\text { vessel(\%) }\end{array}$ & LAD(\%) & $\begin{array}{c}\text { Direct } \\
\text { Stent(\%) }\end{array}$ & $\beta$-blocker(\%) & Statins(\%) & GP(\%) \\
\hline \multicolumn{13}{|l|}{ LPoC } \\
\hline Lonborg $2010^{[21]}$ & 61.5 & 78.0 & 6.9 & 34.8 & 55.1 & 43.2 & 19.5 & 42.0 & 0.0 & 19.5 & 11.9 & 83.1 \\
\hline Sörensson $2010^{[25]}$ & 62.5 & 32.5 & 14.5 & 22.4 & 27.6 & 63.2 & 36.8 & 37.0 & 2.6 & 6.9 & 8.3 & 79.0 \\
\hline Frexia $20122^{[13]}$ & 59.5 & 77.9 & 20.0 & 49.5 & 56.6 & 39.4 & N.A & 30.0 & 58.0 & 26 & 19 & N.A \\
\hline Taraniti $2012^{[14]}$ & 59.6 & 84.6 & 10.3 & 53.9 & 71.8 & 50.0 & 5.1 & 42.0 & 100.0 & 27.0 & 11.5 & 98.7 \\
\hline Thuny $2012^{[26]}$ & 57.0 & 74.0 & 17.0 & 44.0 & 66.0 & N.A & N.A & 56.0 & 100.0 & N.A & N.A & 74.0 \\
\hline Dwyer $2013^{[27]}$ & 57.0 & 88.2 & 9.8 & 37.3 & 44.0 & N.A & N.A & 48.0 & 0.0 & N.A & N.A & 83.3 \\
\hline Limalanathan $2013^{[28]}$ & 60.0 & 82.0 & 3.0 & 26.9 & 51.1 & N.A & 33.1 & 48.0 & 0.0 & N.A & N.A & N.A \\
\hline Elzbieciak $2013^{[29]}$ & 59.2 & 76.9 & 23.1 & 84.6 & 59.0 & 74.4 & 48.7 & 100.0 & 0.0 & N.A & N.A & N.A \\
\hline $\operatorname{Kim} 2015^{[22]}$ & 60.0 & 76.7 & 24.4 & 45.7 & 52.3 & 42.6 & N.A & 46.0 & 13.4 & 100.0 & 100.0 & N.A \\
\hline Bodi $2014{ }^{[30]}$ & 60.0 & 83.0 & 27.0 & 51.0 & 59.0 & 53.0 & 38.0 & N.A & N.A & 80.0 & 89.0 & 60.0 \\
\hline \multicolumn{13}{|l|}{ RPoC } \\
\hline Crimi $2013^{[23]}$ & 58.5 & 87.5 & 12.0 & 53.5 & 53.5 & 31.5 & 35.0 & N.A & N.A & 100 & 100 & 95.5 \\
\hline White $20144^{[24]}$ & 58.4 & 33.6 & 2.93 & 9.93 & 20.5 & 11.4 & N.A & N.A & N.A & N.A & N.A & N.A \\
\hline
\end{tabular}

Note: DM, diabetes mellitus; HP, hypertension; Smk, smoking; DysLip, dyslipidemia; LAD, left anterior descending artery; GP, glycoprotein IIb/IIIa inhibitor ; N.A, not available; LPoC, local ischemic postconditioning; RPoC, remote ischemic postconditioning; Ctrl, control.

related [23, 24] studies. Left ventricular (LV) volume parameters were reportedin ten LPoC-related [13, 14, 22, 25-27, 29, 30] and two RPoC-related [23, 24] studies. Microvascular obstruction (MVO) was reported in seven LPoC-related [13, 14, 22, 25, 30] and RPoC-related $[23,24]$ studies. The Jadad score for ten studies [13, 14, $21-24,26-28,30]$ was $\geq 3$ and 2 for two other studies $[25,29]$.

\section{Effects of ischemic post conditioning on final IS, MSI, and myocardial edema}

As shown in Figure 2, the final IS(\%) was not significantly reduced by $\mathrm{PoC}$ (weighted mean difference
[WMD] $=-1.01 ; 95 \% \mathrm{CI}:-2.95$ to $0.94 ; P>0.05)$ and demonstrated heterogeneity $\left(I^{2}=68.0 \%\right)$. Both LPoC and $\mathrm{RPoC}$ increased the potential of $\mathrm{MSI}(\%)(\mathrm{WMD}=5.52$; 95\% CI: 1.64 to $9.41 ; P=0.005 ; I^{2}=76.0 \%$; Figure $3 \mathrm{~A}$ ). Patients treated by LPoC (WMD $=-2.25 ; 95 \% \mathrm{CI}:-4.71$ to $\left.0.20 ; P=0.07 ; I^{2}=2.0 \%\right)$, or RPoC (WMD $=-5.40$; $95 \% \mathrm{CI}:-8.76$ to $\left.-2.05 ; P=0.002 ; I^{2}=0.0 \%\right)$ showed decreased percent myocardial edema (Figure 3B).

\section{Effect of ischemic postconditioning on LV volume and microvascular obstruction}

PoC did not attenuate left ventricular volume after PCI (standardized mean difference $[\mathrm{SMD}]=-0.09$; 
95\% CI: -0.28 to $0.10 ; P>0.05)$ and showed significant heterogeneity $\left(I^{2}=40.6 \%\right.$; Figure 4). Microvascular obstruction(MVO) was reported in 509 (49.5\%) study subjects. PoC did not reduce the risk of $\mathrm{MVO}(\mathrm{OR}=0.99$; $95 \%$ CI: 0.67 to $1.46 ; P>0.05 ; I^{2}=0.0 \%$; Figure $5 \mathrm{~A}$ ), or the extent of $\mathrm{MVO}(\%)(\mathrm{WMD}=-0.09,95 \% \mathrm{CI}:-0.25$ to 0.07 ; $P>0.05 ; I^{2}=6.0 \%$; Figure 5B).

\section{DISCUSSION}

In this meta-analysis of 12 randomized trials, weassessed 1069 STEMI patients that underwent PCI by cardiac magnetic resonance imaging(cMRI). We observed that both $\mathrm{LPoC}$ and/or RPoC reduced the extent of MSI and myocardial edema, thereby offering cardioprotection. However, LPoC and RPoC did not affect final IS, LV volume, and the incidence or the extent of MVO. This meta-analysis is the first comprehensive analysis to evaluate structural effects of ischemic postconditioning in STEMI patients using cMRI.

The protective potential of ischemic postconditioning (PoC) for STEMI patients has been confirmed in clinical trials by assessing cardiac enzyme levels and left ventricular function $[11,12]$ and systematically reviewed previously [10]. Some trials have explored the structural effects of PoC in STEMI by angiography [13], echocardiography [14, 15] and SPECT [16]. In order to increase the consistency, we included studies that reported structural effects of PoC in STEMI as

Study
ID

Figure 2: Effects of local and remote ischemic postcondtioning on final infarction size. Histogram plots showing final infarction sizes(IS; percentage of left ventricle) in STEMI patients that underwent LPoC and RPoC relative to controls. As shown, ischemic postconditioning $(\mathrm{PoC})$ did not improve IS(weighted mean difference(WMD) $=-1.01 ; P=0.31$ ). Note: LPoC, local ischemic postconditioning; $\mathrm{RPoC}$, remote ischemic postconditioning; PoC, ischemic postconditioning; Ctrl, control. assessed by cMRI, which accurately measures the infarct size and LV volumes [17-19]. Thus, our meta-analysis provides more solid evidence about the structural effects of PoC in STEMI.

During ischemia/reperfusion (I/R), the hydrostatic pressure within interstitial space increases and results in myocardial edema. This contributes to capillary compression and aggravates the extent of cell damage, which is characteristic of severe I/R injury. Since myocardial edema is central to $\mathrm{I} / \mathrm{R}$ injury, it is critical to analyze the positive effects of ischemic postconditioning. In a dog model, ex vivo assessment of water content showed that LPoC reduced myocardial edema [31]. Improved detection of in vivo myocardial edema by non-invasive T2-weighted imaging $[32,33]$ has led to evaluation of the efficacy of ischemic postconditioning on attenuating reperfusion injury $[21,34]$. Thuny et al. showed reduction in the extent of myocardial edema by LPoC in STEMI [26]. However, results of many clinical trials evaluating $\mathrm{LPoC}[21,22,27,30]$ and RPoC [23] have been controversial. In our meta-analysis, we combined positive $[24,26]$ and negative $[21-23,27,30]$ studies and showed that LPoC and RPoC were associated with reduced myocardial edema after STEMI. However, the mechanisms underlying reduced myocardial edema by ischemic postconditioning need further investigation.

To address the effect of cardioprotective interventions on ischemia injury and myocardial edema, we selected T2 weighted cMRI, which is a water-sensitive 
A

Study

$\%$

ID

WMD $(95 \% \mathrm{Cl}) \quad \mathrm{N}$; IsC $\quad \mathrm{N}$; Ctrl Weight

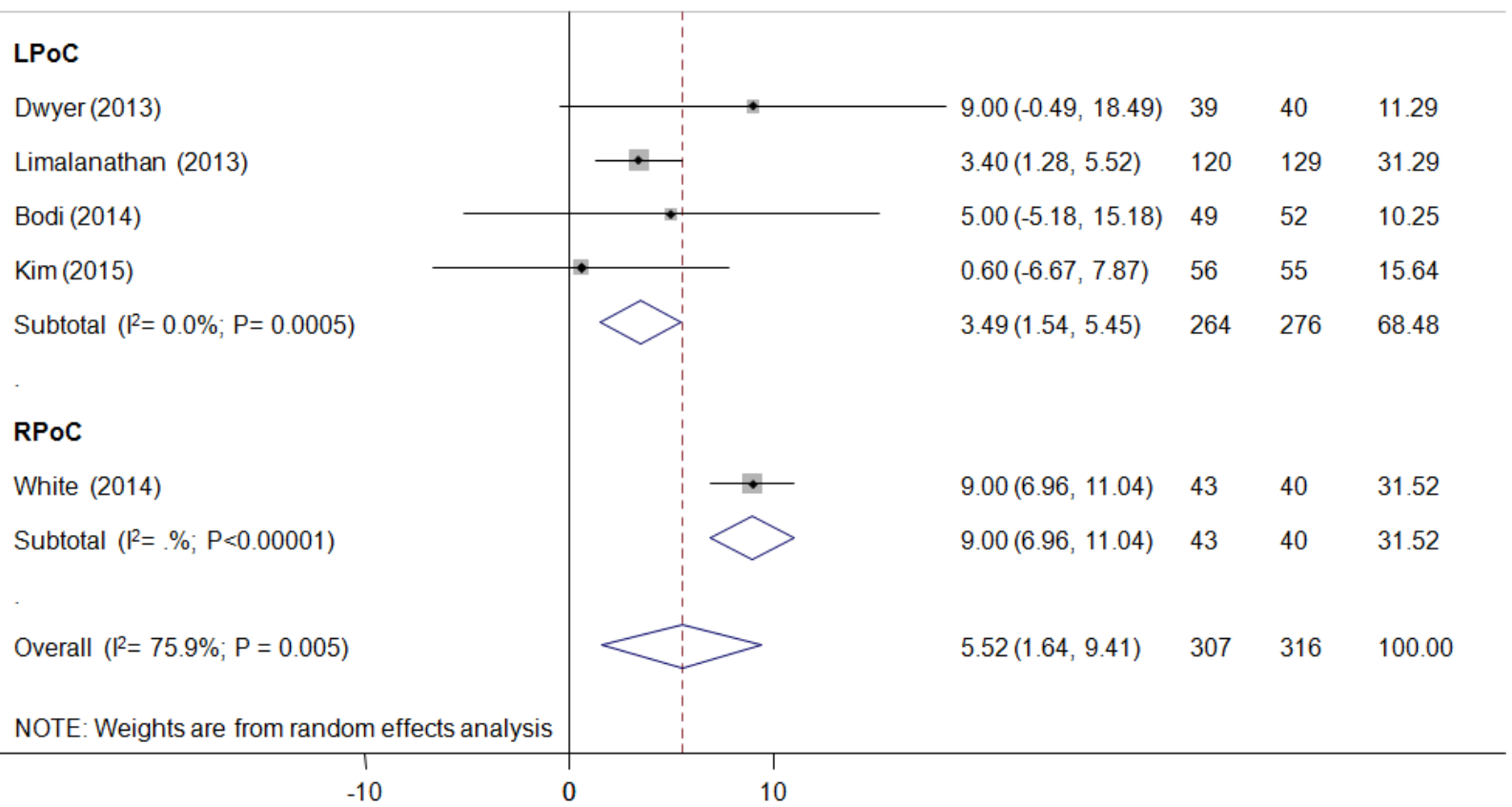

B

Study

ID

WMD $(95 \% \mathrm{Cl})$

$\mathrm{N}$; IsC $\quad \mathrm{N}$; Ctrl Weight

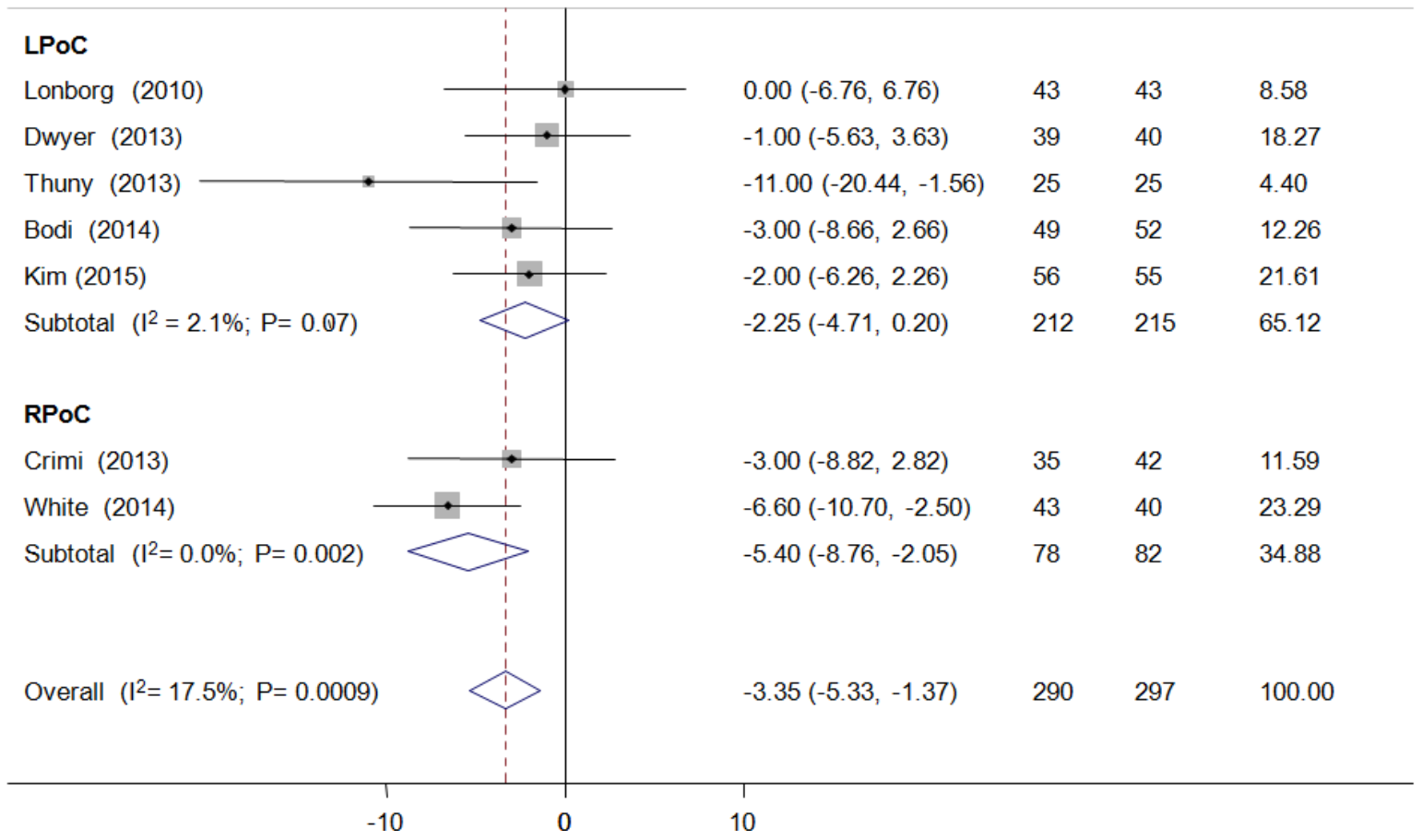

Figure 3: Effects of local and remote ischemic postcondtioning on myocardial salvage and edema. Histogram plots showing that $\mathrm{LPoC}$ and RPoC increased (A) myocardial salvage (percentage of left ventricle; WMD $=5.52 ; P=0.005)$ and reduced $(\mathbf{B})$ myocardial edema(percentage of left ventricle; WMD $=-3.35 ; P=0.0009$ ) in STEMI patients that underwent LPoC and RPoC relative to controls. 
technique that measures myocardial edema in vivo without using radiation or contrast agents and accurately represents the size of area at risk [35]. Our analysis showed that LPoC and RPoC decreased myocardial edema, but did not have any effect on the ischemia. The reasons for these effects are unclear. Myocardial edema includes intracellular and extracellular edema. However, cMRI could not distinguish between the two sources of extracellular edema, namely, intravascular water permeation and water release from necrotic cardiomyocytes into the infarcted area. Reperfusioninduced myocardial edema (extracellular space)increased wall thickness and stiffness favoring collagen deposition and fibrosis, which reduced expansion of the infracted area and left ventricular remodeling, regardless of myocardial salvage [36]. Moreover, recent studies using cMRI have demonstrated a bimodal pattern of myocardial edema after I/R injury, namely, an early phase that is reperfusion induced and occurs within $24 \mathrm{~h}$ and a late phase that represents the auto-healing process lasting at least 7 days $[37,38]$. However, the cMRI assessments were mainly performed within 1 7 days after PCI in the included trials. This suggested that ischemic postconditioning enhanced cardiomyocyte healing without affecting the infarction

Study

ID size. Previous studies have shown that LPoC and RPoC decreases inflammation and reactive oxygen species generation, which may prevent extracellular edema by increasing microvascular permeability [1, 39]. These studies partly explain the dissociation of the beneficial effects of ischemic postconditioning and structural damage in STEMI.

The main strength of our meta-analysis was that we assessed multiple structural parameterssuch as final IS, MSI, left ventricular volume, MVO, and myocardial edema in two settings of ischemic postconditioning namely, LPoC and RPoC using cMRIin STEMI patients. On the other hand, there were several limitations in our study. First, we included veryfew trials and studies and were unable to access individual patient data. Therefore,we may have underestimated the potential influence of comorbid conditions such as diabetes, dyslipidaemia, multi-vessel disease, and LAD as well as effects of cardiovascular medications such as $\beta$-blockers [40], glycoprotein IIb/IIIa inhibitors, and statins [10, 41]. Second, the relative small number of the enrolled subjects may have decreased the statistical power of our results. Third, we applied the random effect model based on $\mathrm{I}^{2} \geq 50 \%$ and assumed normalized distribution

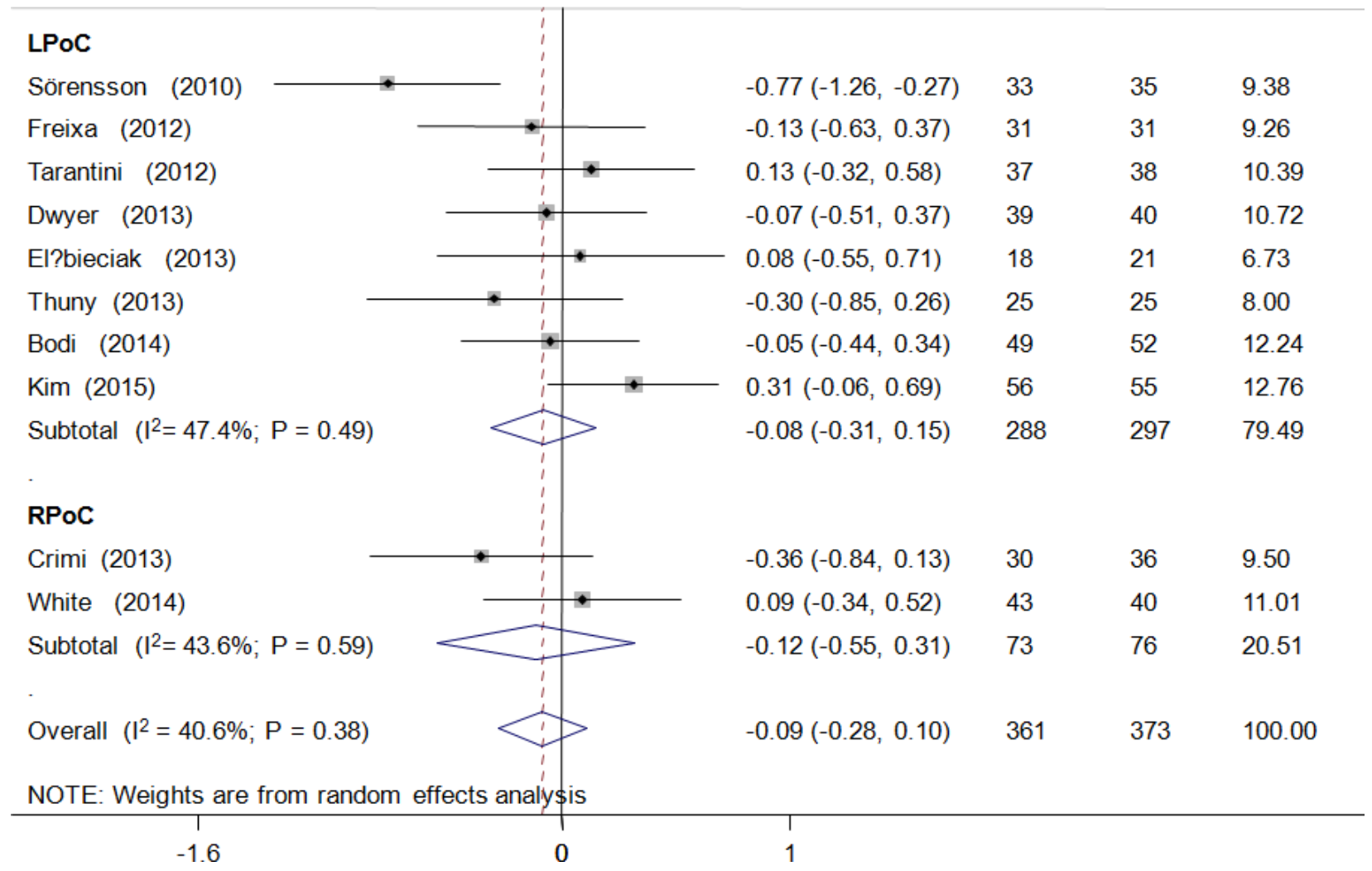

Figure 4: Effects of local and remote ischemic postcondtioning on left ventricular volume. Histogram plots show that LPoC and $\mathrm{RPoC}$ did not reduce left ventricular volume (standardized mean difference(SMD) $=-0.09 ; P=0.38$ ) in STEMI patients that underwent $\mathrm{LPoC}$ and $\mathrm{RPoC}$ relative to controls. 


\section{A}

Study

ID

WMD $(95 \% \mathrm{Cl}) \quad \mathrm{N}$; IsC $\quad \mathrm{N}$; Ctrl Weight

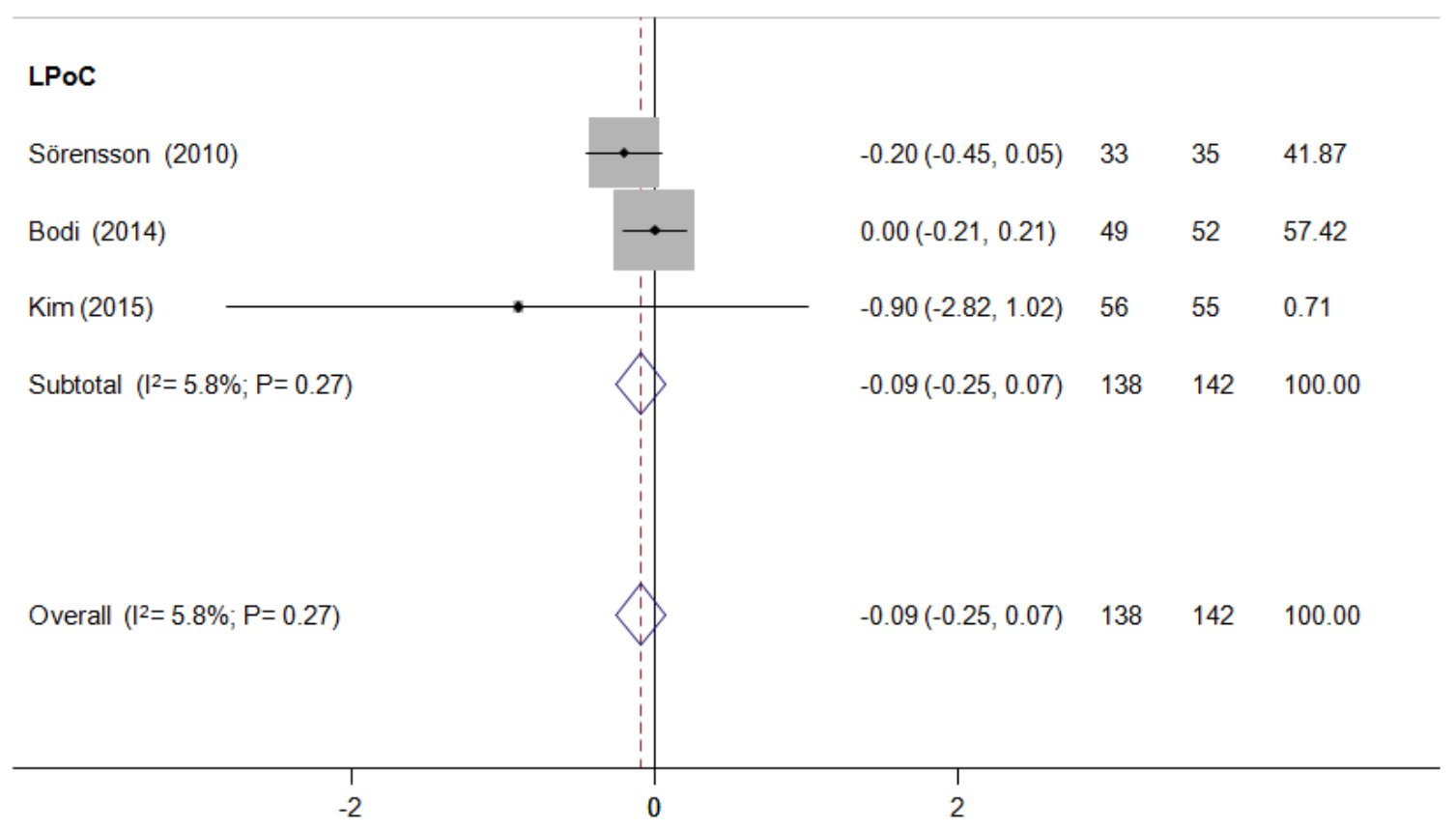

B

Study

ID

$\begin{array}{llll} & \text { Events, } & \text { Events, \% } \\ \text { OR }(95 \% \mathrm{Cl}) & \text { IsC } & \text { Ctrl } & \text { Weight }\end{array}$

LPoC

Freixa (2012)

Tarantini (2012)

Bodi (2014)

Kim (2015)

Subtotal $\left(I^{2}=25.3 \% ; P=0.87\right)$

RPoC

Crimi (2013)

White (2014)

Subtotal $\left(1^{2}=0.0 \% ; P=0.76\right)$

Overall $\left(l^{2}=0.0 \% ; P=0.95\right)$

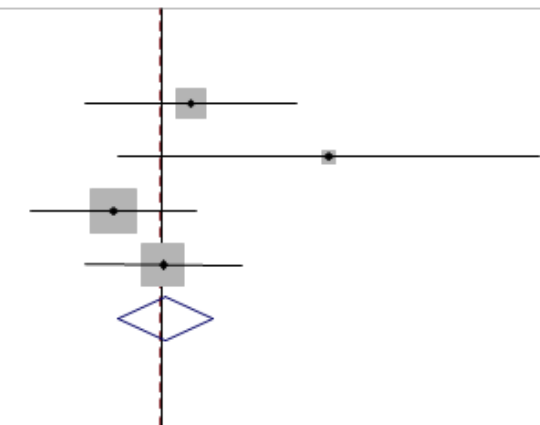

$1.37(0.45,4.12) \quad 23 / 31 \quad 21 / 31 \quad 10.71$

$5.78(0.64,52.10) \quad 5 / 37 \quad 1 / 38 \quad 1.69$

$0.61(0.26,1.46) \quad 12 / 49 \quad 18 / 52 \quad 26.06$

$1.03(0.45,2.33) \quad 40 / 56 \quad 39 / 55 \quad 22.21$

$1.04(0.63,1.71) \quad 80 / 173 \quad 79 / 176 \quad 60.67$

$\begin{array}{cccccc} & & \\ .0192 & 1 & 52.1\end{array}$

Figure 5: Effects of local and remote ischemic postcondtioning on microvascular obstruction. Histogram plots show that $\mathrm{LPoC}$ and RPoC did not reduce $(\mathbf{A})$ extent of microvascular obstruction (WMD $=-0.09 ; P=0.27)$ and $(\mathbf{B})$ the incidence of microvascular obstruction (odds ratio $(\mathrm{OR})=0.99 ; P=0.95$ ]. 
[42]. But, we can't rule out heterogeneity influencing the outcomes of our study. Fourth, we excluded non-English language publications .Fifth, more studies are necessary to assess thec MRI data regarding the effect of ischemic postconditioning on cardiac structurein AMI with baseline TIMI flow grade $2 \sim 3$, especially for RPoC. Finally, the long-term heart failure and cardiac mortality needs to be analyzed and the effect of therapy on cardiac structure needs to be confirmed in future clinical trials.

In conclusion, our meta-analysis of cMRI data showed that both LPoC and/or RPoC reduced the extent of MSI and myocardial edema in STEMI patients. However, there were no improvements in final IS, LV volume, and the incidence or the extent of MVO.

\section{MATERIALS AND METHODS}

\section{Study search strategy and inclusion criteria}

We performed this meta-analysis in accordance with PRISMA (Preferred Reporting Items for Systematic reviews and Meta-Analyses) [43]. We searched PubMed, EMBase, and Cochrane Library databases up to May 2017 with the following keywords:ischemic postconditioning,remote ischemic conditioning, ischemic postconditioning, acute myocardial infarction and percutanenous coronary intervention. Only prospective RCTs that were published in English and that reported STEMI undergoing percutanenous coronary intervention were included in this meta-analysis. Studies those (1) reported only cardiac enzyme levels and/or left ventricular ejection fraction; (2) did not use cMRI for structural assessment and (3) used pre-procedural TIMI flow grade $\geq 2$ for potential spontaneous reperfusion [44] were excluded.

\section{Study selection, quality assessment and data extraction}

Two investigators, Yadong Cui and Haiyang Gao, independently reviewed all abstracts and the full text according to the described search strategy and criteria. In case of disagreements, consensus was achieved by discussion. Quality assessment was performed according to the Jadad scoring system: randomization; blinding; withdrawals and dropouts. Each study obtained a score between 0 and 5 based on withdrawals and dropouts and those with a score $\geq 3$ were considered high-quality [45].

Data extraction included trial design parameters such asyear, country,protocol algorithm, conditioning delay, symptom-to-balloon time, and follow up, and demographic data of patients such as age, gender, and presence or absence of diabetes mellitus, hypertension, smoking, dyslipidemia, stenting technique, multi-vessel, left anterior descending artery disease(LAD), and treatment with glycoprotein IIb/IIIa inhibitor, $\beta$-blockers, and statins.

\section{Evaluation of left ventricular structure by cMRI}

We extracted endpoints assessed by structural cMRI imaging after PCI, which included primary endpoints such as final IS, MSI, and myocardial edema as well as additional endpoints such as LV volume and MVO. The final IS was assessed by late gadolinium enhancement of the cMRI images and expressed as percentage of LV mass [46]. The MSI was defined as the AAR minus IS; AAR was assessed by cMRI [47]. The myocardial edema was expressed as percentage of LV mass and evaluated by the T2 weighted method [33]. The LV volume was recorded as LV end-diastolic volume(LVEDV), or LVEDV index (LVEDVI), which is defined as LVEDV divided by body surface area [20]. The incidence and extent of MVO was expressed as percentage of LV mass and detected by late gadolinium enhancement of the cMRI images [20].

\section{Statistical analysis}

Data was expressed as mean \pm standard deviation or median \pm interquartile range for continuous variables. We calculated WMD or SMD for LVR to obtain the pooled estimates with $95 \%$ confidence intervals (CIs). For dichotomous ones (reported with incidence), we calculated odds ratio (OR) with $95 \%$ CIs. We set $\mathrm{I}^{2} \geq 50.0 \%$ as significant heterogeneity and used random-effects model for analyzing such parameters [48]. $P<0.05$ (2-sided) was considered statistically significant. All statistical analysis was performed by Stata version 9.0(Stata Corporation, College Station, TX) and RevManversion 5.0(Cochrane Collaboration, Oxford, UK) softwares.

\section{Author contributions}

B.L. and M.C: conceptualization, resources, manuscript review and editing, project visualization, supervision and administration; B.L: methodology, software, validation, formal analysis, original manuscript investigation; Y. C. and H.G: data curation; M.C: funding acquisition.

\section{ACKNOWLEDGMENTS AND FUNDING}

This work was supported by the Health Industry Special Scientific Research Project (NO.201402019). We are grateful to Dr. Yadong Cui and Dr. Haiyang Gao from Beijing hospital.

\section{CONFLICTS OF INTEREST}

The authors declare that there are no conflicts of interest. 


\section{REFERENCES}

1. Yellon DM, Hausenloy DJ. Myocardial reperfusion injury. N Engl J Med. 2007; 357:1121-35. https://doi.org/10.1056/ NEJMra071667.

2. Pfeffer MA, Braunwald E. Ventricular remodeling after myocardial infarction. Experimental observations and clinical implications. Circulation. 1990; 81:1161-72. https://doi.org/10.1161/01.CIR.81.4.1161

3. Keeley EC, Boura JA, Grines CL. Primary angioplasty versus intravenous thrombolytic therapy for acute myocardial infarction: a quantitative review of 23 randomised trials. Lancet. 2003; 361:13-20. https://doi. org/10.1016/s0140-6736(03)12113-7.

4. Aurich M, Keller M, Greiner S, Steen H, Aus dem Siepen F, Riffel J, Katus HA, Buss SJ, Mereles D. Left ventricular mechanics assessed by two-dimensional echocardiography and cardiac magnetic resonance imaging: comparison of high-resolution speckle tracking and feature tracking. Eur Heart J Cardiovasc Imaging. 2016; 17:1370-8. https://doi. org/10.1093/ehjci/jew042.

5. Zhao ZQ, Corvera JS, Halkos ME, Kerendi F, Wang NP, Guyton RA, Vinten-Johansen J. Inhibition of myocardial injury by ischemic postconditioning during reperfusion: comparison with ischemic preconditioning. Am J Physiol Heart Circ Physiol. 2003; 285:H579-88. https://doi. org/10.1152/ajpheart.01064.2002.

6. Ovize M, Baxter GF, Di Lisa F, Ferdinandy P, GarciaDorado D, Hausenloy DJ, Heusch G, Vinten-Johansen J, Yellon DM, Schulz R. Postconditioning and protection from reperfusion injury: where do we stand? Position paper from the Working Group of Cellular Biology of the Heart of the European Society of Cardiology. Cardiovasc Res. 2010; 87:406-23. https://doi.org/10.1093/cvr/cvq129.

7. Przyklenk K, Bauer B, Ovize M, Kloner RA, Whittaker P. Regional ischemic 'preconditioning' protects remote virgin myocardium from subsequent sustained coronary occlusion. Circulation. 1993; 87:893-9. https://doi.org/10.1161/01. CIR.87.3.893

8. Hausenloy DJ, Yellon DM. Remote ischaemic preconditioning: underlying mechanisms and clinical application. Cardiovasc Res. 2008; 79:377-86. https://doi. org/10.1093/cvr/cvn114.

9. Heusch G. Molecular basis of cardioprotection: signal transduction in ischemic pre-, post-, and remote conditioning. Circ Res. 2015; 116:674-99. https://doi. org/10.1161/circresaha.116.305348.

10. Zhou C, Yao Y, Zheng Z, Gong J, Wang W, Hu S, Li L. Stenting technique, gender, and age are associated with cardioprotection by ischaemic postconditioning in primary coronary intervention: a systematic review of 10 randomized trials. Eur Heart J. 2012; 33:3070-7. https://doi. org/10.1093/eurheartj/ehs265.

11. Botker HE, Kharbanda R, Schmidt MR, Bottcher M, Kaltoft AK, Terkelsen CJ, Munk K, Andersen NH, Hansen TM,
Trautner S, Lassen JF, Christiansen EH, Krusell LR, et al. Remote ischaemic conditioning before hospital admission, as a complement to angioplasty, and effect on myocardial salvage in patients with acute myocardial infarction: a randomised trial. Lancet. 2010; 375:727-34. https://doi. org/10.1016/s0140-6736(09)62001-8.

12. Prunier F, Angoulvant D, Saint Etienne C, Vermes E, Gilard M, Piot C, Roubille F, Elbaz M, Ovize M, Biere L, Jeanneteau J, Delepine S, Benard T, et al. The RIPOST-MI study, assessing remote ischemic perconditioning alone or in combination with local ischemic postconditioning in STsegment elevation myocardial infarction. Basic Res Cardiol. 2014; 109:400. https://doi.org/10.1007/s00395-013-0400-y.

13. Freixa $X$, Bellera N, Ortiz-Perez JT, Jimenez M, Pare C, Bosch X, De Caralt TM, Betriu A, Masotti M. Ischaemic postconditioning revisited: lack of effects on infarct size following primary percutaneous coronary intervention. Eur Heart J. 2012; 33:103-12. https://doi.org/10.1093/eurheartj/ehr297.

14. Tarantini G, Favaretto E, Marra MP, Frigo AC, Napodano M, Cacciavillani L, Giovagnoni A, Renda P, De Biasio V, Plebani M, Mion M, Zaninotto M, Isabella G, et al. Postconditioning during coronary angioplasty in acute myocardial infarction: the POST-AMI trial. Int J Cardiol. 2012; 162:33-8. https://doi.org/10.1016/j. ijcard.2012.03.136.

15. Zhao CM, Yang XJ, Yang JH, Cheng XJ, Zhao X, Zhou BY, Xu SD, Wang HF. Effect of ischaemic postconditioning on recovery of left ventricular contractile function after acute myocardial infarction. J Int Med Res. 2012; 40:1082-8. https://doi.org/10.1177/147323001204000327.

16. Thibault H, Piot C, Staat P, Bontemps L, Sportouch C, Rioufol G, Cung TT, Bonnefoy E, Angoulvant D, Aupetit JF, Finet G, Andre-Fouet X, Macia JC, et al. Long-term benefit of postconditioning. Circulation. 2008; 117:103744. https://doi.org/10.1161/circulationaha.107.729780.

17. Holman ER, van Jonbergen HP, van Dijkman PR, van der Laarse A, de Roos A, van der Wall EE. Comparison of magnetic resonance imaging studies with enzymatic indexes of myocardial necrosis for quantification of myocardial infarct size. Am J Cardiol. 1993; 71:1036-40. https://doi. org/10.1016/0002-9149(93)90569-X.

18. Thiele H, Kappl MJ, Conradi S, Niebauer J, Hambrecht R, Schuler G. Reproducibility of chronic and acute infarct size measurement by delayed enhancement-magnetic resonance imaging. J Am Coll Cardiol. 2006; 47:1641-5. https://doi. org/10.1016/j.jacc.2005.11.065.

19. Ibrahim T, Bulow HP, Hackl T, Hornke M, Nekolla SG, Breuer M, Schomig A, Schwaiger M. Diagnostic value of contrast-enhanced magnetic resonance imaging and singlephoton emission computed tomography for detection of myocardial necrosis early after acute myocardial infarction. J Am Coll Cardiol. 2007; 49:208-16. https://doi. org/10.1016/j.jacc.2006.08.047.

20. Cerqueira MD, Weissman NJ, Dilsizian V, Jacobs AK, Kaul S, Laskey WK, Pennell DJ, Rumberger JA, Ryan T, 
Verani MS. Standardized myocardial segmentation and nomenclature for tomographic imaging of the heart. A statement for healthcare professionals from the Cardiac Imaging Committee of the Council on Clinical Cardiology of the American Heart Association. Int $\mathrm{J}$ Cardiovasc Imaging. 2002; 18:539-42.

21. Lonborg J, Kelbaek H, Vejlstrup N, Jorgensen E, Helqvist S, Saunamaki K, Clemmensen P, Holmvang L, Treiman M, Jensen JS, Engstrom T. Cardioprotective effects of ischemic postconditioning in patients treated with primary percutaneous coronary intervention, evaluated by magnetic resonance. Circ Cardiovasc Interv. 2010; 3:34-41. https:// doi.org/10.1161/circinterventions.109.905521.

22. Kim EK, Hahn JY, Song YB, Lee SC, Choi JH, Choi $\mathrm{SH}$, Lee SH, Choe YH, Gwon HC. Effect of ischemic postconditioning on myocardial salvage in patients undergoing primary percutaneous coronary intervention for ST-segment elevation myocardial infarction: cardiac magnetic resonance substudy of the POST randomized trial. Int J Cardiovasc Imaging. 2015; 31:629-37. https:// doi.org/10.1007/s10554-015-0589-y.

23. Crimi G, Pica S, Raineri C, Bramucci E, De Ferrari GM, Klersy C, Ferlini M, Marinoni B, Repetto A, Romeo M, Rosti V, Massa M, Raisaro A, et al. Remote ischemic postconditioning of the lower limb during primary percutaneous coronary intervention safely reduces enzymatic infarct size in anterior myocardial infarction: a randomized controlled trial. JACC Cardiovasc Interv. 2013; 6:1055-63. https://doi. org/10.1016/j.jcin.2013.05.011.

24. White SK, Frohlich GM, Sado DM, Maestrini V, Fontana M, Treibel TA, Tehrani S, Flett AS, Meier P, Ariti C, Davies JR, Moon JC, Yellon DM, et al. Remote ischemic conditioning reduces myocardial infarct size and edema in patients with ST-segment elevation myocardial infarction. JACC Cardiovasc Interv. 2015; 8:178-88. https://doi. org/10.1016/j.jcin.2014.05.015

25. Sörensson P, Ryden L, Saleh N, Tornvall P, Arheden H, Pernow J. Long-term impact of postconditioning on infarct size and left ventricular ejection fraction in patients with ST-elevation myocardial infarction. BMC Cardiovasc Disord. 2013; 13:22. https://doi.org/10.1186/1471-226113-22.

26. Thuny F, Lairez O, Roubille F, Mewton N, Rioufol G, Sportouch C, Sanchez I, Bergerot C, Thibault H, Cung TT, Finet G, Argaud L, Revel D, et al. Post-conditioning reduces infarct size and edema in patients with ST-segment elevation myocardial infarction. J Am Coll Cardiol. 2012; 59:2175-81. https://doi.org/10.1016/j.jacc.2012.03.026.

27. Dwyer NB, Mikami Y, Hilland D, Aljizeeri A, Friedrich MG, Traboulsi M, Anderson TJ. No cardioprotective benefit of ischemic postconditioning in patients with ST-segment elevation myocardial infarction. J Interv Cardiol. 2013; 26:482-90. https://doi.org/10.1111/joic. 12064.

28. Limalanathan S, Andersen GO, Klow NE, Abdelnoor M, Hoffmann P, Eritsland J. Effect of ischemic postconditioning on infarct size in patients with ST-elevation myocardial infarction treated by primary PCI results of the POSTEMI (POstconditioning in ST-Elevation Myocardial Infarction) randomized trial. J Am Heart Assoc. 2014; 3:e00679. https://doi.org/10.1161/jaha.113.000679.

29. Elzbieciak M, Wita K, Grabka M, Chmurawa J, Doruchowska A, Turski M, Filipecki A, Wybraniec M, Mizia-Stec K. Effect of postconditioning on infarction size, adverse left ventricular remodeling, and improvement in left ventricular systolic function in patients with first anterior STsegment elevation myocardial infarction. Pol Arch Med Wewn. 2013; 123:268-76. https://doi.org/10.20452/ pamw.1766.

30. Bodi V, Ruiz-Nodar JM, Feliu E, Minana G, Nunez J, Husser O, Martinez-Elvira J, Ruiz A, Bonanad C, Monmeneu JV, Lopez-Lereu MP, Forteza MJ, de Dios E, et al. Effect of ischemic postconditioning on microvascular obstruction in reperfused myocardial infarction. Results of a randomized study in patients and of an experimental model in swine. Int J Cardiol. 2014; 175:138-46. https:// doi.org/10.1016/j.ijcard.2014.05.003.

31. Zhao M, Sonnenblick EH, Zhang H, Eng C. Increase in myofilament separation in the "stunned" myocardium. J Mol Cell Cardiol. 1992; 24:269-76. https://doi. org/10.1016/0022-2828(92)93164-F.

32. Garcia-Dorado D, Oliveras J, Gili J, Sanz E, Perez-Villa F, Barrabes J, Carreras MJ, Solares J, Soler-Soler J. Analysis of myocardial oedema by magnetic resonance imaging early after coronary artery occlusion with or without reperfusion. Cardiovasc Res. 1993; 27:1462-9. https:/doi.org/10.1093/ cvr/27.8.1462.

33. Giri S, Chung YC, Merchant A, Mihai G, Rajagopalan S, Raman SV, Simonetti OP. T2 quantification for improved detection of myocardial edema. J Cardiovasc Magn Reson. 2009; 11:56. https://doi.org/10.1186/1532-429x-11-56.

34. Sanz E, Garcia Dorado D, Oliveras J, Barrabes JA, Gonzalez MA, Ruiz-Meana M, Solares J, Carreras MJ, Garcia-Lafuente A, Desco M, Soler-Soler J. Dissociation between anti-infarct effect and anti-edema effect of ischemic preconditioning. Am J Physiol. 1995; 268:H233-41.

35. Aletras AH, Tilak GS, Natanzon A, Hsu LY, Gonzalez FM, Hoyt RF Jr, Arai AE. Retrospective determination of the area at risk for reperfused acute myocardial infarction with T2-weighted cardiac magnetic resonance imaging: histopathological and displacement encoding with stimulated echoes (DENSE) functional validations. Circulation. 2006; 113:1865-70. https://doi.org/10.1161/ circulationaha.105.576025.

36. Sanz E, Garcia-Dorado D. [Chronic heart failure (X). Ventricular remodelling in myocardial infarct]. [Article in Spanish]. Rev Esp Cardiol. 1992; 45:397-411.

37. Fernandez-Jimenez R, Garcia-Prieto J, Sanchez-Gonzalez J, Aguero J, Lopez-Martin GJ, Galan-Arriola C, MolinaIracheta A, Doohan R, Fuster V, Ibanez B. Pathophysiology Underlying the Bimodal Edema Phenomenon After 
Myocardial Ischemia/Reperfusion. J Am Coll Cardiol. 2015; 66:816-28. https://doi.org/10.1016/j.jacc.2015.06.023.

38. Fernandez-Jimenez R, Sanchez-Gonzalez J, Aguero J, Garcia-Prieto J, Lopez-Martin GJ, Garcia-Ruiz JM, Molina-Iracheta A, Rossello X, Fernandez-Friera L, Pizarro G, Garcia-Alvarez A, Dall'Armellina E, Macaya C, et al. Myocardial edema after ischemia/reperfusion is not stable and follows a bimodal pattern: imaging and histological tissue characterization. J Am Coll Cardiol. 2015; 65:31523. https://doi.org/10.1016/j.jacc.2014.11.004.

39. Prasad A, Stone GW, Holmes DR, Gersh B. Reperfusion injury, microvascular dysfunction, and cardioprotection: the "dark side" of reperfusion. Circulation. 2009; 120:2105-12. https://doi.org/10.1161/circulationaha.108.814640.

40. Zhou C, Liu Y, Yao Y, Zhou S, Fang N, Wang W, Li L. $\beta$-blockers and volatile anesthetics may attenuate cardioprotection by remote preconditioning in adult cardiac surgery: a meta-analysis of 15 randomized trials. J Cardiothorac Vasc Anesth. 2013; 27:305-11. https://doi. org/10.1053/j.jvca.2012.09.028.

41. Ferdinandy P, Hausenloy DJ, Heusch G, Baxter GF, Schulz R. Interaction of risk factors, comorbidities, and comedications with ischemia/reperfusion injury and cardioprotection by preconditioning, postconditioning, and remote conditioning. Pharmacol Rev. 2014; 66:1142-74. https://doi.org/10.1124/pr.113.008300.

42. Deeks J, Higgins J, Altmann D. (2011). Incorporating heterogeneity into random-effects models. In: Higgins J and Green S, eds. Cochrane Handbook for Systematic Reviews of Interventions.

43. Moher D, Liberati A, Tetzlaff J, Altman DG. Preferred reporting items for systematic reviews and meta-analyses: the PRISMA statement. Ann Intern Med. 2009; 151:264-9, W64. https://doi.org/10.7326/0003-4819-151-4-20090818000135 .
44. Roubille F, Mewton N, Elbaz M, Roth O, Prunier F, Cung TT, Piot C, Roncalli J, Rioufol G, Bonnefoy-Cudraz E, Wiedemann JY, Furber A, Jacquemin L, et al. No postconditioning in the human heart with thrombolysis in myocardial infarction flow 2-3 on admission. Eur Heart J. 2014; 35:1675-82. https://doi.org/10.1093/eurheartj/ ehu054.

45. Jadad AR, Moore RA, Carroll D, Jenkinson C, Reynolds DJ, Gavaghan DJ, McQuay HJ. Assessing the quality of reports of randomized clinical trials: is blinding necessary? Control Clin Trials. 1996; 17:1-12. https://doi.org/10.1016/01972456(95)00134-4.

46. Larose E, Rodes-Cabau J, Pibarot P, Rinfret S, Proulx G, Nguyen CM, Dery JP, Gleeton O, Roy L, Noel B, Barbeau G, Rouleau J, Boudreault JR, et al. Predicting late myocardial recovery and outcomes in the early hours of ST-segment elevation myocardial infarction traditional measures compared with microvascular obstruction, salvaged myocardium, and necrosis characteristics by cardiovascular magnetic resonance. J Am Coll Cardiol. 2010; 55:2459-69. https://doi.org/10.1016/j. jacc.2010.02.033.

47. Eitel I, Desch S, Fuernau G, Hildebrand L, Gutberlet M, Schuler G, Thiele H. Prognostic significance and determinants of myocardial salvage assessed by cardiovascular magnetic resonance in acute reperfused myocardial infarction. J Am Coll Cardiol. 2010; 55:2470-9. https://doi.org/10.1016/j.jacc.2010.01.049.

48. Higgins JP, Thompson SG, Deeks JJ, Altman DG. Measuring inconsistency in meta-analyses. BMJ. 2003; 327:557-60. https://doi.org/10.1136/bmj.327.7414.557. 